\title{
Increasing dosages of low-molecular-weight heparin in hospitalized patients with Covid-19
}

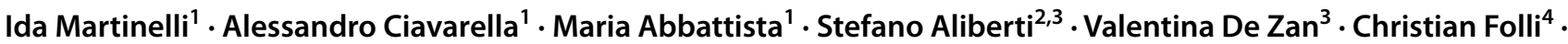 \\ Mauro Panigada ${ }^{5} \cdot$ Andrea Gori $^{3,6} \cdot$ Andrea Artoni $^{1} \cdot$ Anna Maria lerardi $^{7}$. Gianpaolo Carrafiello ${ }^{7} \cdot$ Valter Monzani $^{4}$. \\ Giacomo Grasselli ${ }^{3,5} \cdot$ Francesco Blasi $^{2,3} \cdot$ Flora Peyvandi $^{1,3}$
}

Received: 28 August 2020 / Accepted: 21 November 2020 / Published online: 3 January 2021

(c) Società Italiana di Medicina Interna (SIMI) 2021

\begin{abstract}
We conducted an observational cohort study in adult patients consecutively admitted for the respiratory illness Covid-19 to our hub hospital from March 9 to April 7, 2020. The high observed rate of venous thromboembolism prompted us to increase the prophylactic doses of enoxaparin from $40 \mathrm{mg}$ daily up to $1 \mathrm{mg} / \mathrm{kg}$ twice daily in patients admitted to intensive care units (ICU), $0.7 \mathrm{mg} / \mathrm{kg}$ twice daily in high-intensity of care wards and $1 \mathrm{mg} / \mathrm{kg}$ daily in low-intensity of care wards. Patients on high enoxaparin doses were compared to those who received prophylaxis with the standard dosage. Efficacy endpoints were mortality, clinical deterioration, and the occurrence of venous thromboembolism, safety endpoint was the occurrence of major bleeding. Of 278 patients with Covid-19, 127 received prophylaxis with high enoxaparin doses and 151 with standard dosage. At 21 days, the incidence rate of death and clinical deterioration were lower in patients on higher doses than in those on the standard dosage (hazard ratio 0.39, 95\% confidence interval 0.23-0.62), and the incidence of venous thromboembolism was also lower (hazard ratio 0.52 , 95\% confidence interval $0.26-1.05$ ). Major bleeding occurred in four of 127 patients (3.1\%) on the high enoxaparin dosage. In conclusion, in the cohort of patients with Covid-19 treated with high enoxaparin dosages we observed a $60 \%$ reduction of mortality and clinical deterioration and a $50 \%$ reduction of venous thromboembolism compared to standard dosage prophylaxis. However, $3 \%$ of patients on high enoxaparin dosages had non-fatal major bleeding.
\end{abstract}

Keywords Anticoagulants $\cdot$ Coronavirus $\cdot$ Enoxaparin $\cdot$ Mortality $\cdot$ Venous thromboembolism

Supplementary Information The online version contains supplementary material available at https://doi.org/10.1007/s1173 9-020-02585-9.

Ida Martinelli

ida.martinelli@policlinico.mi.it

1 A. Bianchi Bonomi Hemophilia and Thrombosis Center, Fondazione IRCCS Ca' Granda-Ospedale Maggiore Policlinico, Via Pace 9, 20122 Milan, Italy

2 Respiratory Unit and Cystic Fibrosis Adult Center, Fondazione IRCCS Ca' Granda-Ospedale Maggiore Policlinico, Milan, Italy

3 Department of Pathophysiology and Transplantation, University of Milan, Milan, Italy

4 Department of Medicine-Acute Medical Unit, Fondazione IRCCS Ca' Granda-Ospedale Maggiore Policlinico, Milan, Italy
5 Department of Anesthesia, Intensive Care and Emergency, Fondazione IRCCS Ca' Granda-Ospedale Maggiore Policlinico, Milan, Italy

6 Department of Internal Medicine, Infectious Diseases Unit, Fondazione IRCCS Ca' Granda-Ospedale Maggiore Policlinico, Milan, Italy

7 Radiology Unit, Fondazione IRCCS Ca' Granda-Ospedale Maggiore Policlinico, Milan, Italy 


\section{Introduction}

The pandemic novel coronavirus infection of 2019 (Covid19), caused by the severe acute respiratory syndrome coronavirus 2 (SARS-CoV2), reached Italy on February 21, 2020, when the first patient was diagnosed in Codogno, a city of 16.000 inhabitants in the Lombardy region in the north of the country. Covid-19 rapidly spread in the region, that became the most affected with $27 \%$ of infected persons and $53 \%$ of deaths in the whole country [1]. Our hospital, located in the city center of Milan, became a Covid-19 hub. Since the first few weeks of the emergency, a high mortality rate was recorded particularly in intensive care units (ICU) and high-intensity of care wards. Several patients experiencing a decline in their ability to breathe deteriorated quickly and some died suddenly. In the meantime, autopsy data indicated pulmonary embolism as a frequent fatal event in Covid-19 patients, and the association between marked increases in D-dimer levels and poor prognosis was reported [2-4]. Several risk factors shared by patients hospitalized with Covid19 and those with venous thromboembolism (VTE), such as advanced age, immobilization, admission at ICU, and previous thrombotic events, corroborated our suspicion. We also had the impression that standard prophylactic dosages of low-molecular-weight heparin suggested by the International Society of Thrombosis and Haemostasis [5] were not sufficient to prevent VTE in patients with Covid-19. This impression was supported by the Italian Medicines Agency (AIFA), that encouraged the use of higher doses, close to those used therapeutically [6].

With these uncertainties and gap of knowledge, on March 26,2020 , a collegiate decision was taken in our hub hospital to increase the standard prophylactic doses of low-molecular-weight heparin ( $40 \mathrm{mg}$ daily, to be increased up to $60 \mathrm{mg}$ in obese patients) in all hospital wards and to apply different regimens to patients according to the severity of their infections as witnessed by their admission towards characterized by different levels of care intensity (ICU, high-intensity, and low-intensity of care wards). Accordingly, we chose to compare mortality and the clinical course of patients who received high doses of low-molecular-weight heparin with those who received standard dosage prophylaxis. The two groups were also compared for the occurrence of incident VTE and bleeding episodes.

\section{Methods}

All patients with Covid-19 hospitalized from March 9 to April 7, 2020 in three different intensity of care wards (two ICUs, two high-intensity, and one low-intensity) were included in this cohort study and followed up until April 20, 2020. Patients on standard dosage prophylaxis received enoxaparin $40 \mathrm{mg}$ daily increased to $60 \mathrm{mg}$ daily in obese. Starting from March 26, 2020 the prophylactic doses of enoxaparin were modified. Patients in the ICU received $1 \mathrm{mg} / \mathrm{kg}$ twice daily, those in high-intensity of care wards $0.7 \mathrm{mg} / \mathrm{kg}$ twice daily and those in low-intensity of care wards $1 \mathrm{mg} / \mathrm{kg}$ daily. Clinicians in low-intensity of care wards were invited to obtain the Sequential Organ Failure Assessment (SOFA) score [7] in all patients at admission and during the hospital stay and to increase enoxaparin dosage to $0.7 \mathrm{mg} / \mathrm{kg}$ twice daily in cases with scores higher than six or lower than six but with other risk factors for venous thrombosis such as cancer, obesity (body mass index $>30 \mathrm{~kg} / \mathrm{m}^{2}$ ) or previous venous thrombosis. Exclusion criteria were Covid-19 not confirmed by reverse-transcriptase-polymerase-chain-reaction on the nasal swab, low platelet count $\left(<50 \times 10^{-9} /\right.$ liter $)$ and active bleeding, renal insufficiency (creatinine clearance $<30 \mathrm{~mL} / \mathrm{min}$ ), no prophylaxis or prophylaxis with fondaparinux, and indication for long-term oral anticoagulant therapy. For each patient data were collected from electronic medical records.

Efficacy endpoints were in-hospital mortality, mortality combined with clinical deterioration (i.e., transfer to a higher intensity of care ward) and the occurrence of VTE in patients who received high or standard enoxaparin dosages. The occurrence of bleeding was a safety endpoint. All episodes of symptomatic VTE were objectively confirmed by compression ultrasonography for deep and superficial vein thrombosis, angio-CT scan for pulmonary embolism, and echocardiography for intracardiac thrombi. Compression ultrasonography was performed when signs and symptoms suggestive of vein thrombosis as pain, swelling and skin redness occurred. Angio-CT was performed in case of the rapid deterioration of the patient's respiratory function or for the follow-up of severe pneumonia. Echocardiography was performed for clinical reasons, such as the evaluation of the ejection fraction or the diagnostic evaluation of patients with anamnestic or suspected heart diseases. Bleeding was defined as major or clinically relevant but non-major according to guidelines of the International Society of Thrombosis and Haemostasis [8].

Median and inter-quartile ranges were used to describe continuous variables, counts, and percentages for demographic and clinical variables. Patients' observation started at the time of admission if between March 9 and April 7, 2020, or on March 9 for those already hospitalized and ended at the time of the occurrence of the endpoints, hospital discharge or change in antithrombotic therapy for any clinical reason. Data recording started on March 9 (including already hospitalized patients). Patients with no endpoint were censored on April 20, 2020. Survival functions were 
plotted using the Kaplan-Meier method, while survival analyses were performed using Cox's proportional-hazard regression model. The incidence rates (IR) of the endpoints were calculated with their $95 \%$ confidence intervals (CI) and expressed as events per patient months. Patients admitted before March 26, who possibly received both prophylaxis regimens, were considered in the exposure group to which they contributed for the longest time period, but to reduce a potential survival bias a sensitivity analysis excluding these patients was performed. To reduce a potential immortal bias and to evaluate whether the main results were affected by patients' severity at admission, we also carried out a sensitivity analysis including only patients admitted in the study period, stratified for the first ward intensity of care. All analyses were performed with the statistical software SPSS (release 25.0, IBM SPSS Statistics for Windows, IBM Corp., Armonk, NY, USA).

\section{Results}

\section{Patients}

The whole population of patients hospitalized between March 9 and April 7, 2020 included 460 individuals with Covid-19. After application of the exclusion criteria, 278 patients remained in the study and were followed until April 20, 2020 (Fig. 1). Of them, 127 received high enoxaparin doses (median duration of treatment: 6 days) and 151 standard dosage prophylaxis (median duration of treatment: 10 days). Forty-three patients were hospitalized in ICU, 167 in high-intensity, and 68 in low-intensity care wards. General characteristics, laboratory tests, and type of ventilation at baseline in the different wards, with high and standard enoxaparin dosage prophylaxis are reported in supplements (Table S1). Standard dosage prophylaxis was given to all patients from March 9 to March 26, 2020 and thereafter the

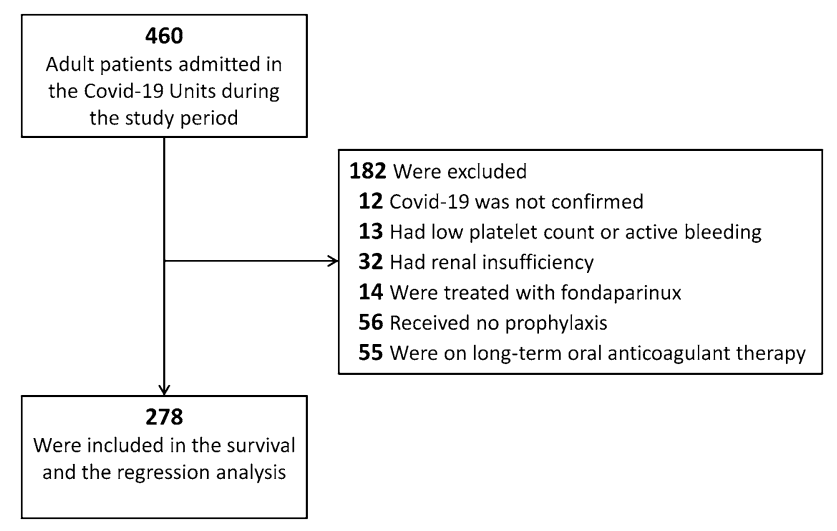

Fig. 1 Study cohort dose was increased for the reasons mentioned above in the three different care intensity wards. The general characteristics, laboratory parameters, and type of ventilation were similar in patients receiving high or standard enoxaparin dosages (Table 1).

\section{Endpoints}

Results of efficacy and safety endpoints are reported in Table 2. Throughout a median follow-up period of 7 days, 12 patients died and other 12 deteriorated in the cohort receiving high enoxaparin dosages compared to 21 and 29 in the cohort who received standard dosage prophylaxis. The cumulative incidence at 21 days and the incidence rate of death were lower in patients treated with high enoxaparin doses than in those with the standard dose, for an adjusted hazard ratio of 0.36 (95\% CI 0.18-0.76) (Fig. 2, panel A). Similar results were obtained by combining deaths with clinical deterioration (adjusted hazard ratio $0.39,95 \% \mathrm{CI}$ 0.23-0.62) (Fig. 2, panel B). The incidence of VTE was lower in patients on high enoxaparin dosages, for an adjusted hazard ratio of 0.52 (95\% CI 0.26-1.05) (Fig. 3). Among patients on high enoxaparin dosages, 11 developed proximal deep vein thrombosis (in five cases catheter-related), one distal deep vein thrombosis, two pulmonary embolisms, two thrombosis of the great saphenous vein, while 16 proximal deep vein thrombosis (in five cases catheter-related), one pulmonary embolism, one intracardiac thrombus and two thrombosis of the great saphenous vein were diagnosed in patients on standard dosage prophylaxis. None of the six pulmonary embolisms was fatal, one was massive involving the pulmonary arteries, two were multiple segmental (in ICU) and three were subsegmental (one in ICU and two in high-intensity of care wards). No patient in the low-intensity care ward developed VTE. Four of 127 patients (3.1\%) on high enoxaparin doses had major bleeding, nonfatal but all requiring red blood cell transfusion. The events were a gluteus hematoma and a hemothorax in two patients in ICU, an iliopsoas, and an upper limb hematoma in a high-intensity of care ward. All bleeding events but hemothorax were spontaneous. No bleeding event was observed in the low-intensity of care ward, nor with standard dosage prophylaxis.

Excluding the 33 patients who received both prophylaxis regimens, we obtained similar results in the main analysis [adjusted hazard ratio 0.39 (95\% CI 0.16-0.93) for death, 0.47 (95\% CI $0.27-0.81$ ) for death and deterioration, and 0.83 (95\% CI 0.41-1.66) for VTE]. The analyses of the same endpoints based upon the first ward of admission were performed in 37 patients admitted to ICU, 110 to high-intensity, and 42 to low-intensity of care wards. The two different enoxaparin regimens influenced the endpoint mortality and clinical deterioration only in the high-intensity of care wards, for a hazard ratio of 0.45 (95\% CI $0.23-0.89)$ in favor 
Table 1 Baseline characteristics of patients receiving high or standard dosage enoxaparin prophylaxis

\begin{tabular}{|c|c|c|c|}
\hline & All patients & High dose & Standard dose \\
\hline No & 278 & 127 & 151 \\
\hline Male sex-no. (\%) & $181(65.1)$ & $82(64.6)$ & $99(65.6)$ \\
\hline Age-yr & $59(49-67)$ & $60(51-69)$ & $58(49-66)$ \\
\hline Body mass index- $-\mathrm{kg} / \mathrm{m}^{2}$ & $27.7(24.7-30.2)$ & $27.0(24.2-30.2)$ & $28.1(25.4-30.2)$ \\
\hline \multicolumn{4}{|l|}{ Comorbidities*— $n(\%)$} \\
\hline None & $119(42.8)$ & $55(43.3)$ & $64(42.4)$ \\
\hline One & $94(32.8)$ & $41(32.3)$ & $53(35.1)$ \\
\hline$\geq$ Two & $65(23.4)$ & $31(24.4)$ & $34(22.5)$ \\
\hline Haemoglobin-g/dL & $12.3(10.9-13.4)$ & $12.3(10.7-13.3)$ & $12.3(11.1-13.5)$ \\
\hline Platelet count $-n / \mathrm{mm}^{3}$ & $257(182-348)$ & $259(171-350)$ & $253(185-341)$ \\
\hline White blood cells $-n / \mu \mathrm{L}^{3}$ & $6.58(4.84-10.13)$ & $6.58(4.66-9.73)$ & $6.56(5.28-10.25)$ \\
\hline Creatinine-mg/dL & $0.84(0.68-1.04)$ & $0.84(0.68-1.00)$ & $0.86(0.68-1.05)$ \\
\hline Lactate dehydrogenase-U/L & $315(253-427)$ & $306(242-417)$ & $326(255-448)$ \\
\hline Prothrombin time-ratio & $1.15(1.07-1.25)$ & $1.13(1.06-1.23)$ & $1.16(1.09-1.27)$ \\
\hline $\begin{array}{l}\text { Activated partial thromboplastin } \\
\text { time-ratio }\end{array}$ & $0.96(0.88-1.04)$ & $0.97(0.88-1.04)$ & $0.995(0.88-1.04)$ \\
\hline Fibrinogen-mg/mL & $550(464-662)$ & $521(442-638)$ & $602(493-684)$ \\
\hline $\mathrm{D}-\mathrm{dimer}-\mu \mathrm{g} / \mathrm{L}$ & $1074(589-2085)$ & $1088(577-2195)$ & $1058(597-1990)$ \\
\hline $\mathrm{C}$ reactive protein $-\mathrm{mg} / \mathrm{dL}$ & $8.69(3.71-14.85)$ & $8.04(3.55-14.40)$ & $9.40(4.13-15.89)$ \\
\hline Ferritin- $\mu \mathrm{g} / \mathrm{L}$ & 1100 (586-1944) & 1117 (544-2118) & $1087(642-1636)$ \\
\hline \multicolumn{4}{|l|}{ Type of ventilation- $n(\%)$} \\
\hline Ambient air & $18(6.5)$ & $13(10.2)$ & $5(3.3)$ \\
\hline Oxygen supplementation & $108(38.8)$ & $56(44.1)$ & $52(34.4)$ \\
\hline High flux nasal cannula & $14(5)$ & $4(3.1)$ & $10(6.6)$ \\
\hline Non-invasive ventilation & $85(30.6)$ & $29(22.8)$ & $56(37.1)$ \\
\hline Endotracheal intubation & $38(13.7)$ & $21(16.5)$ & $17(11.3)$ \\
\hline Missing data & $15(5.4)$ & $4(3.1)$ & $11(7.3)$ \\
\hline
\end{tabular}

Variables are expressed as median (IQR), unless differently specified

*Comorbidities include hypertension, diabetes, chronic lung disease (i.e. asthma, obstructive pulmonary disease, and bronchitis), active cancer, liver disease, systemic autoimmune diseases of high enoxaparin doses. High dosages tended to decrease the incidence rate of VTE more than standard dosages in ICU (hazard ratio $0.53,95 \%$ CI $0.15-1.94$ ) but without influencing mortality. No advantage on efficacy endpoints was seen in the low-intensity of care wards. Three major bleeding events occurred in the first admission ward, two in ICU (gluteus hematoma and hemothorax) and one in a high-intensity of care ward (upper limb hematoma). General characteristics of patients at the time of their first ward of admission and results of the sensitivity analysis are provided in supplements (Table S2, Table S3).

\section{Discussion}

In this observational cohort study involving all patients with Covid-19 hospitalized within a month in three different intensity of care wards of a single hub hospital, we observed lower rates of mortality, clinical deterioration, and VTE in patients receiving high dosage regimens of enoxaparin, tailored on the severity of the disease as witnessed by the intensity of care of the ward, compared to patients receiving standard-dose prophylaxis. Mortality and clinical deterioration were reduced by $60 \%$ and VTE by $50 \%$. However, a small proportion of patients $(3.1 \%)$ on high enoxaparin dosages hospitalized in ICU or high-intensity of care wards developed major bleeding. When we analyzed patients on the basis of the first ward of admission and made a stratified analysis according to the intensity of care, we still observed in high-intensity of care wards an advantage for the high enoxaparin dosages pertaining to death and deterioration, whereas in ICU the advantage was seen only for the prevention of VTE.

Even though the high mortality rate of patients with Covid-19 and its association with an increased risk of VTE is well established, [9-13] limited data on the effect of 
Table 2 Risk of death, death or deterioration, venous thromboembolism, and bleeding

\begin{tabular}{|c|c|c|c|c|}
\hline Death & High dose & Standard dose & $\begin{array}{l}\text { Crude analysis Hazard } \\
\text { ratio }(95 \% \mathrm{CI})\end{array}$ & $\begin{array}{l}\text { Multivariable analysis } \\
\text { Hazard ratio }(95 \% \\
\text { CI)* }\end{array}$ \\
\hline No. of events/no. patient-days & $12 / 1472$ & $21 / 1141$ & & \\
\hline Cumulative incidence at 21 days (\%) & $15.0(6.0-24.0)$ & $22.0(12.3-31.6)$ & & \\
\hline Incidence rate (95\% CI) (patient-months) & $0.25(0.13-0.43)$ & $0.56(0.36-0.84)$ & $0.48(0.23-0.98)$ & $0.36(0.18-0.76)$ \\
\hline \multicolumn{5}{|l|}{ Death or deterioration } \\
\hline No. of events/no. patient-days & $24 / 1472$ & $50 / 1141$ & & \\
\hline Cumulative incidence at 21 days $(\%)$ & $23.6(14.0-33.2)$ & $40.2(30.6-49.8)$ & & \\
\hline Incidence rate $(95 \% \mathrm{CI})$ (patient-months) & $0.49(0.32-0.72)$ & $1.33(1.00-1.73)$ & $0.45(0.27-0.73)$ & $0.39(0.23-0.62)$ \\
\hline \multicolumn{5}{|l|}{ Venous thromboembolism } \\
\hline No. of events/no. patient-days & $16 / 1472$ & $20 / 1141$ & & \\
\hline Cumulative incidence at 21 days (\%) & $22.2(10.4-34.0)$ & $31.6(6.3-56.9)$ & & \\
\hline Incidence rate $(95 \% \mathrm{CI})$ (patient-months) & $0.33(0.20-0.52)$ & $0.53(0.33-0.80)$ & $0.62(0.31-1.24)$ & $0.52(0.26-1.05)$ \\
\hline \multicolumn{5}{|l|}{ Bleeding } \\
\hline No. of events/no. patient-days & $4 / 1472$ & $0 / 1233$ & & \\
\hline Cumulative incidence at 21 days $(\%)$ & $4.6(0.0-10.3)$ & 0.0 & & \\
\hline Incidence rate $(95 \% \mathrm{CI})$ (patient-months) & $0.08(0.03-0.20)$ & 0.00 & - & - \\
\hline
\end{tabular}

*Hazard ratio for the multivariable Cox proportional-hazard model including adjustment for age, sex, body mass index and comorbidities (dichotomic variable defined by the presence of $<2$ or $\geq 2$ comorbidities)

antithrombotic prophylaxis on the clinical outcome in Covid19 are currently available. In China, there was a difference between heparin users and non-users on the 28-day mortality in a sub-group of patients meeting the criteria of sepsisinduced coagulopathy (SIC) or with a sixfold increased levels of D-dimer [14], but it remains to be established whether these results may be translated to Caucasian populations, which seldom develop disseminated intravascular coagulation $[15,16]$. A difference in mortality between patients who received antithrombotic prophylaxis with therapeutic doses and those who received no antithrombotic prophylaxis has been reported only in patients on invasive mechanical ventilation (29 vs $63 \%$ ), with a rate of $3 \%$ of major bleeding similar to that observed in our patients receiving the high enoxaparin dosage [17]. This figure is similar or even lower to that observed in critically ill patients on standard prophylaxis [18]. Although the safety of high doses of LMWH needs to be assessed by means of randomized controlled trials, perhaps the observed low bleeding rate may be due to the hypercoagulable state typical of patients with severe Covid-19 patients [19, 20].

This observational study compared standard dosage prophylaxis with high dose regimens of enoxaparin, that we were prompted to evaluate by our unfavorable early clinical experience. Its main limitation is that the employed dosage regimens were not randomly assigned to consecutive patients, even though the baseline characteristics of patients were comparable between the two groups on standard or high dosage prophylaxis. Hence, our results should be taken as proof of concept for a randomized clinical trial. Other limitations need to be addressed. Our selection criteria led to the exclusion of approximately $40 \%$ of patients of the whole cohort, limiting the generalizability of the results but also reducing the occurrence of confounding factors. Second, the incidence rate of fatal pulmonary embolism remains unknown because autopsies were not carried out. Another limitation is that the analyses on the first ward of admission (presented in supplements) are less robust than the main analyses owing to the small number of cases. Other potential unknown or unrecorded confounders, such as an increased experience in the care of patients with Covid-19 and change in pharmacological treatments, may have influenced our findings. However, all patients requiring respiratory support received non-invasive ventilation or orotracheal intubation as needed.

In conclusion, with all the limitations of a non-randomized study, we observed that patients with Covid-19 receiving high doses of enoxaparin tailored to the severity of their clinical conditions had reduced mortality, clinical deterioration, and VTE by approximately 50-60\% compared to patients on standard doses. Particular attention should be 

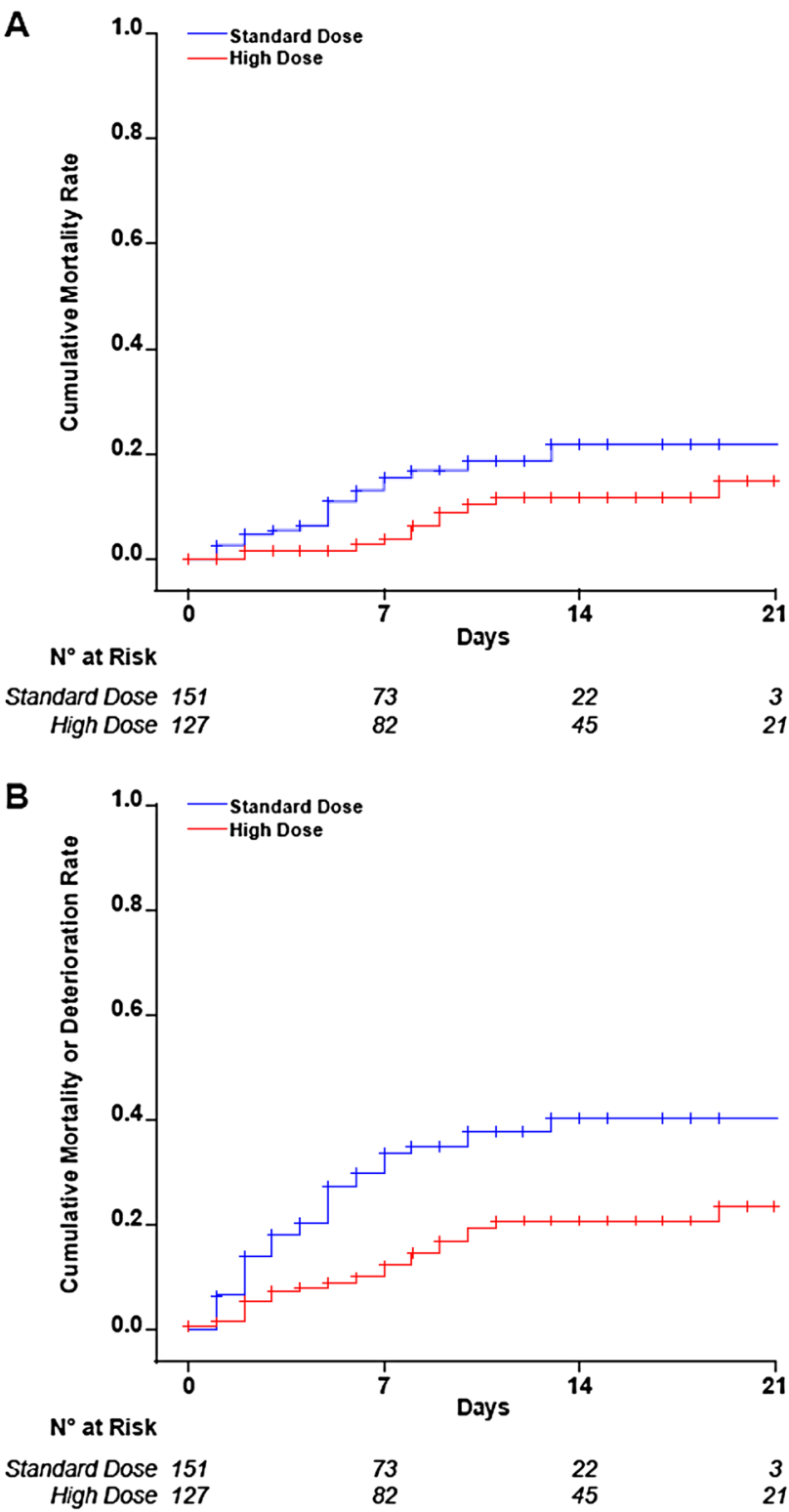

Fig. 2 Cumulative incidence of mortality and mortality or clinical deterioration. Plots of the efficacy endpoints mortality (panel A) and mortality plus clinical deterioration (panel B) with the different dosage regimens of enoxaparin

paid to the most critically ill patients hospitalized in ICU or high-intensity care wards, who may develop life-threatening bleedings. Results from randomized clinical trials are warranted to establish the optimal prophylactic enoxaparin dose in patients with COVID-19.

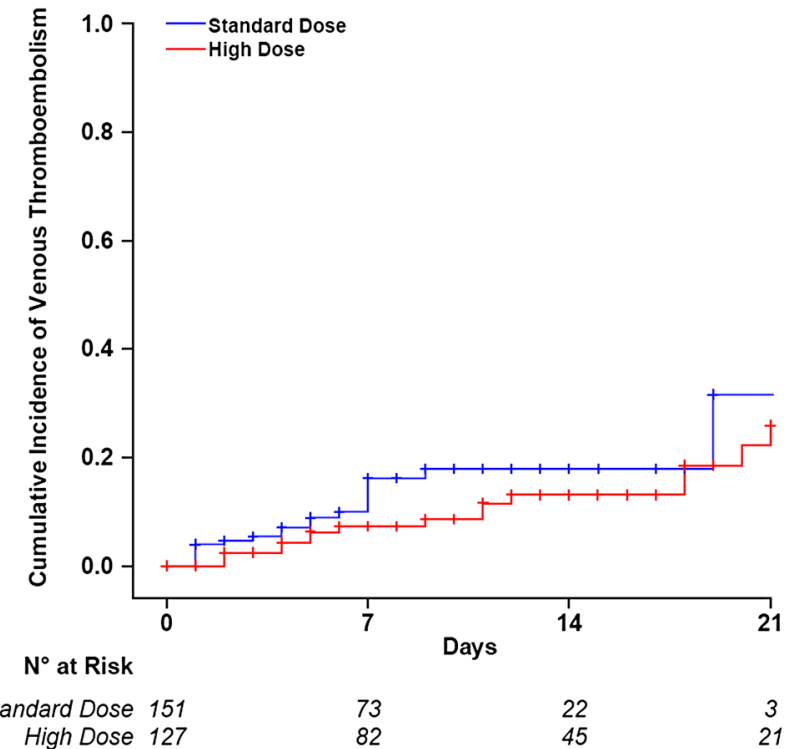

Fig. 3 Cumulative incidence of venous thromboembolism

Acknowledgements We thank Prof. P.M. Mannucci for the critical revision of the manuscript and Dr. P. Bucciarelli for his help in statistical analyses. We thank all the medical students of the university hospital who, albeit exhausted for working on shifts, collected data in the respective wards. This work is dedicated to the victims of Covid-19 in the city of Milan, in Northern Italy, and in the whole country, health care workers and patients. To their families goes our comfort.

Authors contributions IM had full access to all the data in the study and takes responsibility for the integrity of the data and the accuracy of the data analysis. IM, AC, and MA contributed to design the study, perform the statistical analysis, and develop the manuscript, drafting and revising the text, tables, and figures. SA, VDZ, CF, MP, AG, AA, AMI contributed to the acquisition, interpretation of data, and critically reviewed the manuscript for important intellectual content. IM, FP, GC, VM, GG, and FB supervised the study and critically reviewed the manuscript for important intellectual content. All authors read and approved the final manuscript for submission.

Funding This study was supported by Italian Ministry of HealthBando Ricerca Corrente, Fondazione IRCCS Ca' Granda-Ospedale Maggiore Policlinico.

\section{Compliance with ethical standards}

Conflict of interest FP reports advisory fees from Bioverativ, Roche, Sanofi, Takeda, and Sobi outside of the submitted work. IM reports personal and non-financial support from Bayer and Roche outside of the submitted work. All other authors declare no competing interests. 
Ethics approval The study protocol was conducted in accordance with the Declaration of Helsinki and was approved by the local ethics committees Milano Area 2 (ethics approval number 446_2020).

Human and animal rights This article does not contain any studies with animals performed by any of the authors.

Informed consent This study was conducted on already available clincal data and informed consent was not required.

\section{References}

1. Odone A, Delmonte D, Scognamiglio T, Signorelli C (2020) COVID-19 deaths in Lombardy, Italy: data in context. Lancet Public Health. https://doi.org/10.1016/S2468-2667(20)30099-2

2. Poissy J, Goutay J, Caplan M, Parmentier E, Duburcq T, Lassalle F, Jeanpierre E, Rauch A, Labreuche J, Susen S, Lille ICUHC-g (2020) Pulmonary embolism in COVID-19 patients: awareness of an increased prevalence. Circulation. https://doi.org/10.1161/ CIRCULATIONAHA.120.047430

3. Yao XH, Li TY, He ZC, Ping YF, Liu HW, Yu SC, Mou HM, Wang LH, Zhang HR, Fu WJ, Luo T, Liu F, Chen C, Xiao HL, Guo HT, Lin S, Xiang DF, Shi Y, Li QR, Huang X, Cui Y, Li XZ, Tang W, Pan PF, Huang XQ, Ding YQ, Bian XW (2020) A pathological report of three COVID-19 cases by minimally invasive autopsies. Zhonghua Bing Li Xue Za Zhi 49:E009. https:// doi.org/10.3760/cma.j.cn112151-20200312-00193

4. Wichmann D, Sperhake JP, Lutgehetmann M, Steurer S, Edler C, Heinemann A, Heinrich F, Mushumba H, Kniep I, Schroder AS, Burdelski C, de Heer G, Nierhaus A, Frings D, Pfefferle S, Becker H, Bredereke-Wiedling H, de Weerth A, Paschen HR, Sheikhzadeh-Eggers S, Stang A, Schmiedel S, Bokemeyer C, Addo MM, Aepfelbacher M, Puschel K, Kluge S (2020) Autopsy findings and venous thromboembolism in patients with COVID-19: a prospective cohort study. Ann Intern Med. https://doi.org/10.7326/ M20-2003

5. Thachil J, Tang N, Gando S, Falanga A, Cattaneo M, Levi M, Clark C, Iba T (2020) ISTH interim guidance on recognition and management of coagulopathy in COVID-19. J Thromb Haemost 18(5):1023-1026. https://doi.org/10.1111/jth.14810

6. Ciavarella A, Peyvandi F, Martinelli I (2020) Where do we stand with antithrombotic prophylaxis in patients with COVID19? Thromb Res 191:29. https://doi.org/10.1016/j.throm res.2020.04.023

7. Vincent JL, de Mendonca A, Cantraine F, Moreno R, Takala J, Suter PM, Sprung CL, Colardyn F, Blecher S (1998) Use of the SOFA score to assess the incidence of organ dysfunction/failure in intensive care units: results of a multicenter, prospective study. Working group on "sepsis-related problems" of the European Society of Intensive Care Medicine. Crit Care Med 26(11):17931800. https://doi.org/10.1097/00003246-199811000-00016

8. Kaatz S, Ahmad D, Spyropoulos AC, Schulman S, Subcommittee on Control of A, (2015) Definition of clinically relevant nonmajor bleeding in studies of anticoagulants in atrial fibrillation and venous thromboembolic disease in non-surgical patients: communication from the SSC of the ISTH. J Thromb Haemost 13(11):2119-2126. https://doi.org/10.1111/jth.13140

9. Klok FA, Kruip M, van der Meer NJM, Arbous MS, Gommers D, Kant KM, Kaptein FHJ, van Paassen J, Stals MAM, Huisman MV, Endeman H (2020) Confirmation of the high cumulative incidence of thrombotic complications in critically ill ICU patients with COVID-19: an updated analysis. Thromb Res. https://doi. org/10.1016/j.thromres.2020.04.041

10. Helms J, Tacquard C, Severac F, Leonard-Lorant I, Ohana M, Delabranche X, Merdji H, Clere-Jehl R, Schenck M, Fagot Gandet F, Fafi-Kremer S, Castelain V, Schneider F, Grunebaum L, Angles-Cano E, Sattler L, Mertes PM, Meziani F, Group CT (2020) High risk of thrombosis in patients with severe SARSCoV-2 infection: a multicenter prospective cohort study. Intensive Care Med. https://doi.org/10.1007/s00134-020-06062-x

11. Middeldorp S, Coppens M, van Haaps TF, Foppen M, Vlaar AP, Muller MCA, Bouman CCS, Beenen LFM, Kootte RS, Heijmans J, Smits LP, Bonta PI, van Es N (2020) Incidence of venous thromboembolism in hospitalized patients with COVID-19. J Thromb Haemost. https://doi.org/10.1111/jth.14888

12. Marietta M, Coluccio V, Luppi M (2020) COVID-19, coagulopathy and venous thromboembolism: more questions than answers. Intern Emerg Med. https://doi.org/10.1007/s11739-020-02432-x

13. Giorgi-Pierfranceschi M, Paoletti O, Pan A, De Gennaro F, Nardecchia AL, Morandini R, Dellanoce C, Lombi S, Tala M, Cancelli V, Zambelli S, Bosio G, Romanini L, Testa S (2020) Prevalence of asymptomatic deep vein thrombosis in patients hospitalized with SARS-CoV-2 pneumonia: a cross-sectional study. Intern Emerg Med. https://doi.org/10.1007/s11739-020-02472-3

14. Tang N, Bai H, Chen X, Gong J, Li D, Sun Z (2020) Anticoagulant treatment is associated with decreased mortality in severe coronavirus disease 2019 patients with coagulopathy. J Thromb Haemost 18(5):1094-1099. https://doi.org/10.1111/jth.14817

15. Lodigiani C, Iapichino G, Carenzo L, Cecconi M, Ferrazzi P, Sebastian T, Kucher N, Studt JD, Sacco C, Alexia B, Sandri MT, Barco S, Humanitas C-TF (2020) Venous and arterial thromboembolic complications in COVID-19 patients admitted to an academic hospital in Milan, Italy. Thromb Res 191:9-14. https://doi. org/10.1016/j.thromres.2020.04.024

16. Fogarty H, Townsend L, Ni Cheallaigh C, Bergin C, MartinLoeches I, Browne P, Bacon CL, Gaule R, Gillett A, Byrne M, Ryan K, O'Connell N, O'Sullivan JM, Conlon N, O'Donnell JS (2020) COVID19 coagulopathy in Caucasian patients. Br J Haematol. https://doi.org/10.1111/bjh.16749

17. Paranjpe I, Fuster V, Lala A, Russak A, Glicksberg BS, Levin MA, Charney AW, Narula J, Fayad ZA, Bagiella E, Zhao S, Nadkarni GN (2020) Association of treatment dose anticoagulation with in-hospital survival among hospitalized patients with COVID-19. J Am Coll Cardiol. https://doi.org/10.1016/j.jacc.2020.05.001

18. Group PIftCCCT, the A, New Zealand Intensive Care Society Clinical Trials G, Cook D, Meade M, Guyatt G, Walter S, HeelsAnsdell D, Warkentin TE, Zytaruk N, Crowther M, Geerts W, Cooper DJ, Vallance S, Qushmaq I, Rocha M, Berwanger O, Vlahakis NE (2011) Dalteparin versus unfractionated heparin in critically ill patients. N Engl J Med 364(14):1305-1314. https:// doi.org/10.1056/NEJMoa1014475

19. Coccheri S (2020) COVID-19: The crucial role of blood coagulation and fibrinolysis. Intern Emerg Med. https://doi.org/10.1007/ s11739-020-02443-8

20. Peyvandi F, Artoni A, Novembrino C, Aliberti S, Panigada M, Boscarino M, Gualtierotti R, Rossi F, Palla R, Martinelli I, Grasselli G, Blasi F, Tripodi A (2020) Hemostatic alterations in COVID-19. Haematologica. https://doi.org/10.3324/haema tol.2020.262634

Publisher's Note Springer Nature remains neutral with regard to jurisdictional claims in published maps and institutional affiliations. 